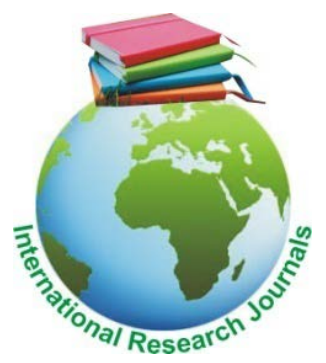

Full Length Review Paper

Journal of Research in Environmental Science and Toxicology Vol. 7(2) pp. 41-46, Dec, 2018

DOI: http:/dx.doi.org/10.14303/jrest.2018.019

Available online http://www.interesjournals.org/JREST

Copyright (C2018 International Research Journals

\title{
Determination of heavy metals concentration in traditional medicinal plants Ziziphus spina- christi, Withania somnifera and Ximenia americana by inductively coupled plasma optical emission spectrometery in Amhara Region of Ethiopia
}

\author{
Getaw Ayele ${ }^{1}$, Kusse Gudishe ${ }^{2 *}$ \\ ${ }^{1}$ Department of Physics, College of Natural and Computational Sciences, Dilla University, Ethiopia \\ ${ }^{2}$ Department of Physics, College of Natural and Computational Sciences, Wolaita Sodo University, Ethiopia, \\ anaxorma@gmail.com
}

\begin{abstract}
The study of traditional medicinal plants attracted concerns of many researchers because they are not rigorously regulated. On the other hands, their potentiality for medicine use is still predominant in different part of the world today. In this study, heavy metals (copper, zinc, nickel and lead) concentrations were determined using inductively coupled plasma optical emission spectroscopy in three traditional medicinal plants: Ziziphus spina-christi, Ximenia americana, and Withania somnifera in northern part of Ethiopia. Microwave digestion procedure was applied under optimized conditions for digesting medicinal herbs. All the four heavy metals have been detected in this experiment. Results revealed that two of the investigated medicinal plants Ziziphus spina-christi and Winthania somnifera have showed concentrations within permissible levels for all the elements. The concentration of lead in Ximenia americana indicated a potential health risk to consumers in area as it was observed to be $55.20 \pm 0.01$ ppm.
\end{abstract}

Keywords: Medicinal plants, Inductively coupled plasma optical emission spectroscopy, Heavy metals, concentration, Permissible level

\section{INTRODUCTION}

Use of traditional medicinal plant has long history in human life. The interest is steadily increasing due to increased cases of bacteria resistance to current pharmaceuticals, affordability and readily availability (Abas, 2001; Ernst and White, 2000). About 70\%-80\% of the world population continues to rely on non conventional medicines which predominately consist of herbal sources in their primary health care (Inamdar et al., 2008). The study of traditional medicines is of special concern because they are not rigorously regulated thus the focus of this study was to determine the amount of toxic heavy metals in fresh roots of three selected medicinal plants: Ziziphus spina-christi, Withania somnifera and Ximenia americana using inductively coupled Plasma optical emission spectrometer at Kewet Wereda, North Shewa Zone, Amhara region of Ethiopia.
The three plants may have different nomenclatures in different languages. In Amharic Ximenia americana is named "Eenkoy". Its fruit is eaten in Ethiopia. People traditionally use fresh root of this plant for liver case treatment. Fresh root part of this plant is grounded and dilute with hot water to drink for the treatment. Withania somnifera, named "Gizawa" in Amharic, is used for the treatment of stomach ache. People simply digest the fresh root part of this plant in mouth and swallow the water. Ziziphus spina- christi known as "Kurkura" in Amharic is a tropical plant whose fruit is eaten. Its fresh root is used for liver worse treatment the same as Ximenia americana in northern part of Ethiopia.

Herbal medicines are likely to be contaminated with heavy metals (Saeed et al., 2010; Kiran et al., 2011). In trace amounts of some heavy metals are essential for the human body, however, they may be toxic if present 
in a higher concentration (Lalla et al., 2001). They have the ability to bio-accumulate and disrupt functions of vital organs and glands in the human body such as brain, kidney and liver (Suranjana and Manas, 2009). Medicinal plants can be contaminated by heavy metals via roots uptake or by direct deposition of contaminants from the atmosphere onto plant surface. And the usage of fresh roots of such medicinal plants requires carful treatment.

Among toxic metals lead, copper, nickel, zinc and lead are considered in the work. Lead, one of the heavy metals, is considered a potential carcinogen and is associated with many diseases which include cardiovascular, kidney, blood, nervous, and bone diseases (Jarup, 2003). Lead is a protoplasmic poison with affinity for the grey matter of brains. It invades neurons, damages cells, nerve synapse and dendrites, and reduces the number of oxygen carrying red blood cells (Ferner, 2000; Ogwuegbu and Muhanga, 2005). It combines with phosphorous and enters the blood stream where it goes to the spleen, liver, and kidneys (Ferner, 2000). Excessive concentration of zinc and copper in the body is of great concern because of their toxicity to humans and animals (Kabata-Pendias and Mukherjee, 2007).

Medicinal plants play an important role from the ancient period as they are used in traditional medicine and also as home remedies. Environment, pollution, atmosphere, soil, harvesting and handling are some of the factors, which play a major role in contamination of medicinal plants by metals and also by microbial growth. Therefore, it is necessary to measure and establish the levels of metallic elements in the herbal plants as these elements when consumed at higher levels become toxic. The World Health Organization also emphasized the need to ensure the quality of plant and its products by using modern techniques and applying suitable standards (Al Moaruf et al., 2004).

Traditional medicine has a significant contribution to the global health care system (Chan, 2003) when their levels controlled. A significant proportion of the world's population relies on traditional medicine to support their basic health care needs (Jayaraj, 2010). Therefore, safety and qualities of such products become major concern (Igweze et al., 2012). Inorganic contaminants such as heavy metals are often present in herbal medicine in various concentration levels (Qing-hua, 2001). The presence of heavy metals in such products is either referred to the ingredients itself or they might arise during the processing part (Sharma and Dubey, 2005; Uddin et al., 2012). Prolonged exposure to these metals may cause many adverse health effects including cancer (Ray and Ray, 2009). Consequently, heavy metal content in traditional medicine products must be accurately determined. Highly sensitive spectroscopic techniques such as Flame Atomic Absorbtion Spectroscopy (FAAS), Graphite Furnace Atomic
Absorbtion Spectroscopy (GFAAS) and Hydride Generation Atomic Absorption Spectrometry (HGAAS) are mainly applied for elemental analysis in various samples. Such techniques require aqueous samples. Thus, solid samples need to be regularly converted into solutions using an appropriate dissolution method (Charun and John, 2006).

Traditional medicinal plants play vital role treating various human ailments in Ethiopia for long by traditional experts. The skill and knowledge of preparations and dosages are not scientific. As a result the preparation and dosage of the plant medicines may affect human health immediately after treatment or even fetal occasionally. The harmful nature of these plants may be resulted from heavy metal contents present in traditional medicinal plant that are toxic and harmful to human health even in low concentration. There should be technological advancements to improve the safety and quality of traditional medicinal plants to reduce the health risks.

\section{METHODS AND MATERIALS}

\section{Sample Preparations}

Samples were taken from fresh root parts of Ziziphus spina-christi, Ximenia american, and Withania somnifera which were collected from Amhara Region of Ethiopia. The root parts of the plants were taken and washed first with clean water. Then the flashy parts next to the cell walls were taken by cleaned knives similarly and separately for all samples. The samples were about $20 \mathrm{~g}$ for each and these wet samples were placed on clean plates separately. The plates were placed in shadow area at home room temperature to minimize the volatility of elements under investigation. The samples were dried for about 20 days and the dried samples were grinded in to homogeneous fine powder. Then the powdered samples were stored in separate clean bottles for metal analysis.

\section{Sample Digestion Procedures}

Microwave digestion procedure was applied under optimized conditions for digesting medicinal herbs. A $0.5 \mathrm{~g}$ of the plant sample was accurately weighed into a digestion tube followed by addition of $8 \mathrm{~mL}$ of concentrated nitric acid $\left(\mathrm{HNO}_{3}\right)$ and $2 \mathrm{~mL}$ of concentrated hydrogen peroxide $\left(\mathrm{H}_{2} \mathrm{O}_{2}\right)$ (Sigma Aldrich) similarly for all samples. The mixtures were closed and subjected to milestone start D microwave digester (Switzerland) with maximum temperature of $250^{\circ} \mathrm{C}$ and of pressure 1200 psi for fifteen minutes. At the end of irradiation cycle, samples were cooled to room temperature and transferred to $50 \mathrm{~mL}$ Erlenmeyer flask and diluted with $2 \%$ nitric acid solution and filtered through $0.45 \mu \mathrm{m}$ pore diameter membrane to avoid possible contaminations.

\section{Experimental Setup}

The absorption spectrums of concentration of metals in 
the samples were recorded using ICPOES (Agilent 700 series, USA). Digested sample was transported into ICPOES as a stream of liquid and it was converted into an aerosol through a nebulizer into spray chamber. Argon gas supply was used to form plasma. The sample aerosol was transported to the argon plasma where it was desolated, vaporized, atomized and excited or ionized by the plasma. The excited atoms and ions emitted their characteristic radiation which was collected by a device that sorted the radiation by wavelength. The radiation was detected and turned into electronic signals that were converted into concentration information for the analysts from calibration curves of each element displayed in Figure 1.

\section{Statistical Analysis}

All measurements were done in triplicates and expressed as mean \pm standard deviations. Data were analyzed using one-way analysis of variance (ANOVA) at level of $5 \%$ ( $p$ $\leq 0.05$ ) followed by least significant difference Post Hoc test in Microsoft Excel for the determination of statistical significance of a given metal across the samples, not within a given sample. Data were further manipulated with ASA and SPSS statistics 20 as well as Origin pro 8 software was also used in this work.

\section{RESULTS AND ANALYSIS}

\section{Standard Solutions}

In order to determine the concentration of each heavy metal, standard solutions were prepared from which calibrations curves were plotted. From the calibration curves concentration of each sample was determined. Figure 2 presents the calibration curves of the copper heavy metal (although it was construct for all samples) undergone investigations in this work.

\section{Concentration of Heavy Metals}

Concentrations of four heavy metals were determined in the three medicinal plants considered in this work. Results of heavy metal concentrations determination in the selected raw medicinal plant samples are presented in Table 1.

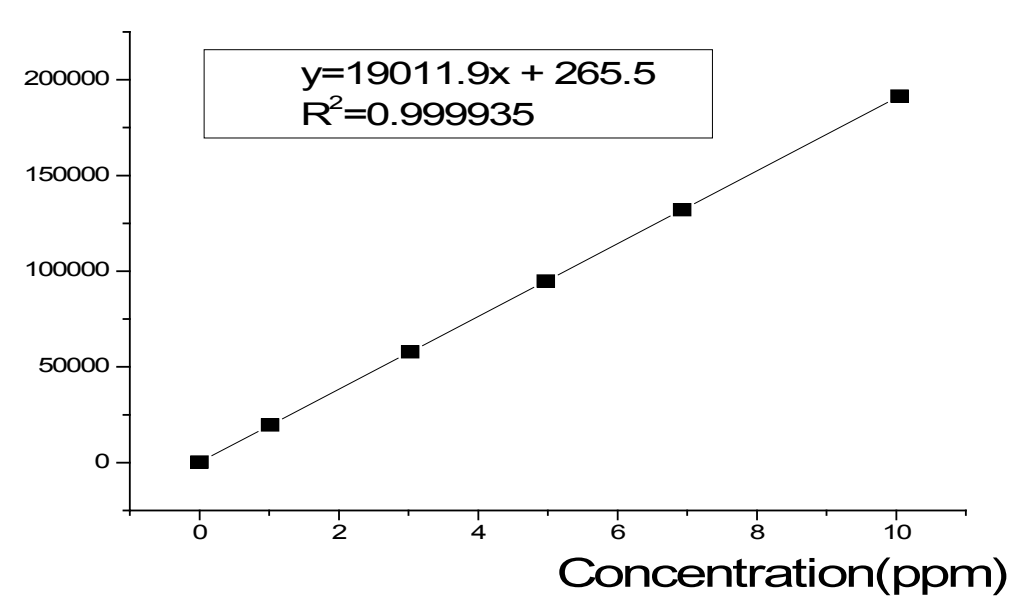

Figure 1. Calibration curves for copper standard solution

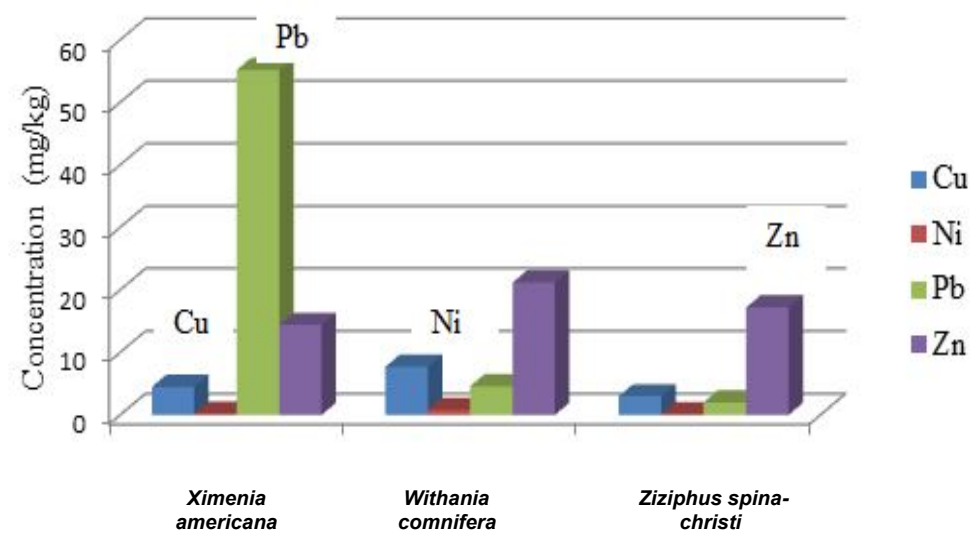

Figure 2. Concentration comparison of the heavy metals. 
Table 1. ASA and SPSS mean concentration ( $\mathrm{ppm}$ ) of heavy metals in fresh roots of traditional medicinal plants in this work.

\begin{tabular}{|l|c|c|c|c|}
\hline Traditional Medicinal Plant & Copper & Nickel & Lead & Zinc \\
\hline Ximenia americana & $4.50 \pm 0.00^{\mathrm{B}}$ & $0.20 \pm 0.00^{\mathrm{B}}$ & $55.20 \pm 0.01^{\mathrm{A}}$ & $14.40 \pm 0.00^{\mathrm{C}}$ \\
\hline Withania somnifera & $7.70 \pm 0.00^{\mathrm{A}}$ & $0.800 .00^{\mathrm{A}}$ & $4.60 \pm 0.02^{\mathrm{B}}$ & $21.20 \pm 0.00^{\mathrm{A}}$ \\
\hline Ziziphus spina-christi & $3.00 \pm 0.00^{\mathrm{C}}$ & $0.10 \pm 0.00^{\mathrm{CB}}$ & $2.00 \pm 0.00^{\mathrm{CB}}$ & $17.20 \pm 0.00^{\mathrm{B}}$ \\
\hline LSD $^{1}$ & 0.34 & 0.02 & 0.61 & 0.10 \\
\hline CV $^{2}$ & 10.56 & 3.12 & 12.55 & 6.13 \\
\hline F Value & 35.45 & 412.03 & 28.39 & 102.55 \\
\hline
\end{tabular}

${ }^{1}$ least significant differences, ${ }^{2}$ covariant value, a means with the same letter have no statistical significances among different plants.

As can be seen from Table 1, Withania somnifera contained 7.70 ppm of copper, 0.80 ppm of nickel, 4.60 ppm of lead and 21.20 ppm of zinc. The medicinal plant Ximenia americana showed concentration of $4.50 \mathrm{ppm}$ and 0.20 of copper and nickel, respectively. Moreover, it conitains $55.20 \mathrm{ppm}$ and $14.40 \mathrm{pmm}$ of lead and zinc concentrations. Ziziphus spina-christi was seen to contain 3.00 ppm and 0.10 ppm of copper and nickel, respectively. In addition, this plant was observed to contain 2.00 ppm and 17.20 ppm of lead and zinc concentrations.

Lead presents in high amount in Ximenia americana (55.20 $\pm 0.01 \mathrm{ppm}$ ) as compared to the rest of the two traditional medicinal plants considered in this work. On the other hand, Ziziphus spina-christi is observed to contain less concentration of all the samples, except for zinc $(17.20 \pm 0.00 \mathrm{ppm})$, which is indicated to be less in Ximenia americana plant (21.20 \pm 0.00 ppm).

One-way Analysis of Variance (ANOVA) at level of 5\% ( $p$ $\leq 0.05$ ) taken in order to see the significance difference of all the elements considered in this work for different plants. It can be seen from Table 1, that Withania somnifera has got significantly high concentration, except. In top of indicating the significance difference, letters $A$, $B$ and $C$ shows that the plant with letter ' $A$ ' in a specific element determination shows the higher concentration. And element with letter 'B' follows. Consequently, all the four metals have got statistically significant difference in all the three medicinal plants.

\section{DISCUSSIONS}

Copper mean concentration was found to be higher $(7.70 \pm 0.00 \mathrm{ppm})$ in Withania somnifera as compared to Ximenia americana and Ziziphus spina-christi. As can be seen from Figure 2, however, it falls in normal level which is in the range 3-15 mg/kg when treated for human health effect. The mean concentration of copper in this experiment was observed in Ziziphus spina -christi (3.00 \pm $0.00 \mathrm{ppm}$ ) traditional medicinal plant but is in permissible range (De Feo et al., 2007). Ximenia americana contains $(4.50 \pm 0.00 \mathrm{ppm})$ mean concentration of copper which was found to be a value between the one found in other two plants. Copper concentration of Ziziphus spina-christi two times less than that of Withania somnifera. The copper concentration obtained in north Western Libya for four medicinal plants ranged from $0.02-0.99 \mathrm{mg} / \mathrm{kg}$. This falls to the lower end of this work that ranged 0.30-7.70 $\mathrm{mg} / \mathrm{kg}$ (Abdul-fattah Alkherraz, 2015). Report in india on traditionally used herb Ceropegia juncea (Roxb.) plant indicated $1.64 \mathrm{mg} / \mathrm{kg}$ (Karayil, 2014) which is lower than the one found in this work. Researches done in Pakistan on determination of heavy metals presented that copper concentration in the range of $1.01-4.67 \mathrm{mg} / \mathrm{kg}$ (lqbal et al., 2013) that fits to present work.

Nickel is a trace element and its minimal risk level was set to be $0.2 \mu \mathrm{g} / \mathrm{m}^{3}$, however, no limit has been set for food stuffs (Kim et al., 2008). In the present investigation, averagely maximum $(0.80 \pm 0.00 \mathrm{ppm}) \mathrm{Ni}$ concentration was found in Withania somnifera. Nickel concentration was 4-8 folds more in Withania somnifera than the other two medicinal plants underwent investigation in this work. Less mean concentration of $\mathrm{Ni}$ was observed in Ziziphus spina-christi $(0.10 \pm 0.00 \mathrm{ppm})$ whereas $(0.20 \pm 0.00)$ mean concentration of $\mathrm{Ni}$ was measured in Ximenia americana. lqbal and other researchers reported that concentration of nickel metal in herbal medicinal plants determined in Pakistan was in the range of $2.98-4.01 \mathrm{mg} /$ $\mathrm{kg}$ (lqbal et al., 2013). This result is in good agreement with current work.

Lead is highly toxic for plants, animals and microorganisms. The plant roots tested in this experiment contained extremely higher mean concentrations of lead (55.20 $\pm 0.01 \mathrm{ppm}$ ) in Ximenia americana as compared to the permissible limit of 20 ppm defined by World Health Organization (WHO) (De Feo et al., 2007; Bhat et al., 2010). Minimum amount of lead was found in Ziziphus spina-christi (2.00 $\pm 0.00 \mathrm{ppm})$. In Withania somnifera traditional plant investigated in this work contained mean lead concentration of ( $4.60 \pm 0.01 \mathrm{ppm})$. Except the one found in Ximenia americana, the mean concentrations of lead found in other two plants experimented in this work were found to be in the normal concentration range (Bhat et al., 2010). In experiments conducted in north western India, the average concentration of lead was found to be $(0.81 \pm 0.04 \mathrm{ppm})$ in leaf samples and $(2.64 \pm 0.03$ ppm) in stems for Withania somnifera (WHO, 2007). Results found in this work also agree with work of Munish and Ravikant (Alpana et al., 2013). Table 2 presents limit, permissible range of heavy metals concentration. 
Table 2. WHO concentration limits, permissible ranges of heavy metals in plants (De Feo et al., 2007; Bhat et al., 2010).

\begin{tabular}{|c|c|c|c|c|c|c|}
\hline \multirow[t]{2}{*}{ Metals } & \multicolumn{3}{|c|}{ Concentration $(\mathrm{mg} / \mathrm{kg})(\mathrm{ppm})$ in this work } & \multicolumn{2}{|c|}{$\begin{array}{c}\text { Concentration (mg/kg) } \\
(\mathrm{ppm})\end{array}$} & \multirow[t]{2}{*}{ Permissible range } \\
\hline & Ximenia americana & Withania somnifera & Ziziphus spina-christi & Normal & Toxic & \\
\hline $\mathrm{Cu}$ & $4.50 \pm 0.00$ & $7.70 \pm 0.00$ & $3.00 \pm 0.00$ & $3-15$ & 20 & $2-5$ \\
\hline $\mathrm{Ni}$ & $0.20 \pm 0.00$ & $0.80 \pm 0.00$ & $0.10 \pm 0.00$ & $0.02-50$ & - & \\
\hline $\mathrm{Pb}$ & $55.20 \pm 0.01$ & $4.60 \pm 0.01$ & $2.00 \pm 0.00$ & $1-5$ & 20 & $0.50-30$ \\
\hline $\mathrm{Zn}$ & $14.40 \pm 0.00$ & $21.20 \pm 0.00$ & $17.20 \pm 0.00$ & $15-150$ & 200 & $20-100$ \\
\hline
\end{tabular}

Concentrations of lead found in Abdul-fattah et al. (0.04$0.76 \mathrm{mg} / \mathrm{kg}$ ) (Abdul-fattah et al., 2013) and Karayil et al. $(0.002 \mathrm{mg} / \mathrm{kg}$ ) (Karayil et al., 2014) best agree with result of current work (0.10-0.80 mg/kg).

Zinc is a ubiquitous trace element essential as a catalytic, structural, and regulatory ion, is indispensable for growth and development of microorganisms, plants, and animals (Munish and Ravikant, 2014). Average human intake of zinc ranges between 2.5 and $10 \mathrm{mg} /$ day (KabataPendias, 2011). Its antioxidant function is attributed to its function of blocking the negatively charged sites, thereby preventing lipid per oxidation. Its deficiency has mostly been associated with increase in the levels of lipid per oxidation of mitochondrial and microsomal membranes along with osmotic fragility of the erythrocyte membrane. The concentration of zinc in this experiment ranges from $(14.40 \pm 0.00-21.20 \pm 0.00 \mathrm{ppm})$. More mean concentration was found in Withania somnifera (21.20 $\pm 0.00 \mathrm{ppm}$ ) while averagely less zinc concentration was found in Ziziphus spina-christi (17.20 $\pm 0.00 \mathrm{ppm})$. The mean concentration of zinc in Ximenia americana was in between the two $(14.40 \pm 0.00 \mathrm{ppm})$. Kulhari et al. investigated concentration of zinc in Withania somnifera and found results that agree with results of this work. They found zinc concentration was $(4.10 \pm 0.04 \mathrm{ppm})$ in leafs and $(8.93 \pm 0.03 \mathrm{ppm})$ in stems. Results found in this work also agree with work of Munish, Ravikant and different countries have set different limit on this element (WHO, 2007). Concentrations of zinc found in Abdulfattah et al. (0.03-11.30 mg/kg) (Abdul fattah et al., 2013) and Karayil et al. (0. $32 \mathrm{mg} / \mathrm{kg}$ ) (Karayil et al., 2014) were found to be lower than result of this work (14.40-21.20 $\mathrm{mg} / \mathrm{kg}$ ). However, lqbal et al. (Iqbal et al., 2013) reported $(13.70-40.34 \mathrm{mg} / \mathrm{kg})$ which is in good agreement with present report.

As can be seen from Figure 2, the toxic lead leads the race of concentration and it is found in Ximenia americana. Nickel was found to be comparatively less in all the three plants. Except in Ximenia americana, concentration of zinc was found to be higher. Lead concentration was less in Ziziphus spina-Christi as compared to other two plants investigated in this work.

As can be seen from Table 1, the mean concentrations of copper and zinc found in the three traditional medicinal plants have showed statistical significance. Lead has showed statistical significance in Ximenia americana while nickel was observed to have statistical significance in Withania somnifera. The concentrations of the traditional medicinal could be related with acidity of soil contamination and exchangeable fraction of heavy metals in soil as reports presented by Glavač and coworkers (Glavač et al., 2017).

\section{CONCLUSIONS}

Heavy metals (copper, zinc, nickel and lead) concentrations were determined using inductively coupled plasma optical emission spectroscopy in three traditional medicinal plants: Ziziphus spina-christi, Ximenia Americana, and Withania somnifera in Amhara Region of Ethiopia. Two of the investigated medicinal plants Ziziphus spinachristi and Winthania somnifera have showed level of concentration of the metals within permissible levels for all the elements underwent test in this work. The concentration of lead in Ximenia americana (55.20 \pm $0.01 \mathrm{ppm}$ ) indicated a potential health risk to consumers.

\section{ACKNOWLEDGMENTS}

This work has been supported by Ministry of Education, Ethiopia.

\section{REFERENCES}

Abas HH (2001). Adverse effects of herbs and drugherbal interaction. Malaysian. J. Pharm. 1: 39-44.

Abdulfattah MA, Almahdi MA, Adel MM (2013). Determination of Some Heavy Metals in Four Medicinal Plants. World Acad. Sci. Eng. Techno. 78: 1568-1570.

Al Moaruf OA, Muibat OB, Asiata OI, Isiaka AO, Nureni OO (2004). Food Chem. 85, 67-71.

Alpana K, Arun S, Somvir B, Susheel S, Ashok C, Rajwant KK (2013). Investigation of heavy metals in frequently utilized medicinal plants collected from environmentally diverse locations of north western India. Springer Plus 2: 676

Bhat R, Kiran K, Arun AB, Karim AA (2010). Determination of mineral composition and heavy metal content of some nutraceutically valued plant products. Food Anal. Meth. 3: 181-187.

Chan K (2003). Some aspects of toxic contaminants in herbal medicines. Chemosphere. 52: 1361-71. 
Charun Y, John GF (2006). Comparative study of acid-extractable and total digestion. methods for the determination of inorganic elements in peat material by inductively coupled plasma-optical emission spectrometry. Anal. Chim. Acta. 557: 296-303.

DeFeo CJ, Aller SG, Unger VM (2007). A structural perspective on copper uptake in eukaryotes. Biometal 20: 705-716.

Ernst E and White AR (2000). The BBC survey of complementary medicine use in the UK, Complement. Med. 8: 32-36.

Ferner DJ (2000). Toxicity, heavy metals. eMed. J. 2: 1.

Glavac NK, Djogo S, Ražić S, Kreft S, Veber M (2017). Accumulation of heavy metals from soil in medicinal plants, Arch. Hyg. Indu. Toxicol. 68: 236-244

Igweze ZN, Orisakwe OE, Obianime A (2012). Nigerian herbal remedies and heavy metals: violation of standard recommended guidelines. Asian Pac. J. Trop. 2:1423-1430.

Iqbal M, Khattak B, Ayaz S, Rehman A, Ishfaq M, Abbas MN, Malik MS, Wahab A, Imran, Mehsud S (2013). Pollution Based Study of Heavy Metals in Medicinal plants Aloe vera and Tamarix aphylla, J. Appl. Pharm. Sci. 3: 054-058.

Inamdar N, Edalat S, Kotwal VB, Pawar S (2008). Herbal drugs in milieu of modern drugs. Int. J. Green Pharm. 2(1): 2-9.

Jarup L (2003). Hazards of heavy metal contamination. British Medical Bulletin. 68(1):167-182.

Jayaraj P (2010). Regulation of traditional and complementary medicinal products in Malaysia. Int. J. Green. Pharm. 4:10-14.

Kabata-Pendias A and Mukherjee AB (2007). Trace elements from soil to human. New York, Springer-Verlag.

Kabata-Pendias A (2011). Trace Elements in Soils and Plants, 4th ed. CRC Press, Boca Raton, Florida, USA.

Karayil S, Bhavani, Ch V (2014). Heavy Metal Analysis from Traditionally used Herb Ceropegia juncea (Roxb.). IOSR J. Pharm. 4: 7-11.

Kim BE, Nevitt T, Thiele DJ (2008). Mechanisms of copper acquisition, distribution and regulation. Nat. Chem. Biol. 4: 176-185.

Kiran YK, Mir AK, Rabia N, Mamoona M, Hina F, Paras M, Nighat S, Tasmia B, Ammarah K, Sidra NA (2011). Element content analysis of plants of genus icus using atomic absorption spectrometer. Afr. J. Pharm. Pharmacol. 5: 317-321.

Lalla JK, Hamrapurkar PD, Mamania HM (2001). Triphala Churna from raw materials to finished products. Indian Drugs. 38: 87-94.

Munish G, Ravikant (2014). Screening of Indian Withania Plant and marketed products for trace elements, heavy metals for quality and efficacy. J. Pharm. Phytochem. 2: 66-68.

Ogwuegbu MOC, Muhanga W (2005). Investigation of Lead Concentration in the Blood of People in the Copper belt Province of Zambia. J. Environ. 1: 66-75.

Qing-hua Y, Qing W, Xiao-qin M (2001). Determination of major and trace elements in six herbal drugs for relieving heat and toxicity by ICP-AES with microwave digestion. J Saudi Chem. Soc. 16: 287-290.

Ray SA, Ray MK. (2009). Bioremediation of heavy metal toxicity-with special reference to chromium. Ameen. J. Med. Sci. 2: 57-63.

Saeed M, Muhammad N, Khan H (2010). Analysis of toxic heavy metals in branded Pakistani herbal products. J. Chem. Soc. Pakistan. 32: 471-475.

Sharma P, Dubey RS (2005). Lead toxicity in plants. Braz. J. Plant Physiol. 17: 35-52.

Suranjana AR and Manas KR (2009). Bioremediation of Heavy Metal Toxicity-With Special Reference to Chromium. Al Ameen. J. Med. Sci. 2: 57 -63.

Uddin AB, Khalid RS, Abba S (2012). Determination of heavy metal concentration of different traditional medicine formulations available at the East Coast Region of Malaysia. Afr. J. Pharm. Pharacol. 6:1487-91.

WHO (2007). Guidelines for assessing quality of herbal medicines with reference to contaminants and residues. World Health Organization, Geneva. 